\title{
Responding to project uncertainty: Evidence for high reliability practices in large-scale safety-critical projects
}

Fiona C Saunders ${ }^{\mathrm{a}}{ }^{1}$, Andrew W Gale ${ }^{\mathrm{a}}$ and Andrew H Sherry ${ }^{\mathrm{b}}$

a School of Mechanical, Aerospace and Civil Engineering, The University of Manchester, Pariser Building, Sackville Street, Manchester M13 9PL, United Kingdom

${ }^{\mathrm{b}}$ Dalton Nuclear Institute, The University of Manchester, Pariser Building, Sackville Street, Manchester, M13 9PL, UK

${ }^{\mathrm{c}}$ National Nuclear Laboratory, Chadwick House, Warrington Road, Birchwood Park, Warrington, WA3 6AE, United Kingdom

\begin{abstract}
In large-scale safety-critical projects unforeseen events and uncertainties must be carefully managed to safeguard the integrity of the end product and deliver projects to time and cost. Based on 47 'vignettes' of uncertainty across projects in two safety-critical sectors, this study provides an empirical examination of whether practices consistent with theories of high reliability organising are adopted by project managers as a response to project uncertainty. Our findings are that confronting uncertainties in safety-critical projects does involve many high reliability practices. Respondents expressed a sense of balancing competing demands, and provided evidence of learning, acting mindfully, avoiding over-rigid processes, and of upholding constructive tensions, conceptual slack and close interdisciplinary working.
\end{abstract}

However these practices are often fragile in nature and dependent on key individuals. There are also differences between the two sectors studied, with more widespread evidence of high reliability project organising in civil nuclear than in aerospace projects.

\section{Keywords}

Projects; high reliability organising, safety-critical, uncertainty

\footnotetext{
${ }^{1}$ Corresponding Author at: School of Mechanical, Aerospace and Civil Engineering, The University of Manchester, Pariser Building, Sackville Street, Manchester M13 9PL, UK. Tel 0044161 3063738: Email: fiona.saunders@manchester.ac.uk
} 


\section{Introduction}

Designing the next generation civil airliners, constructing new nuclear power plants and safely decommissioning former civil nuclear assets are all large-scale safety-critical projects that must be completed in a safe, yet timely manner. However, the uncertainties in these projects are numerous and non-trivial in nature. For example, what is the condition of the radioactive waste that needs to be removed from a decades old storage pond; or what are the performance trade-offs and design implications in bringing ever lighter and more fuel efficient aircraft into service? Barton, Sutcliffe, Vogus, \& Dewitt (2015) argue that performance in these uncertain contexts is "a situation specific accomplishment that involves managing contradictions and interruptions" (Barton et al., 2015,p75) and that high reliability theory provides a theoretical framework for how this may be achieved. To date, however, most research into high reliability organisations has focused on high hazard operations (cf. La Porte, 1988; Mannarelli, Roberts, \& Bea, 1996; Roberts \& Bea, 2001; Rochlin, La Porte, \& Roberts, 1987; Roe \& Schulman, 2008; Schulman, 1993) and there is little prior work on high reliability organising in the project context. Saunders (2015) argued that safety-critical projects - like operations - are complex, highly consequential, and under tremendous pressure to deliver safe outcomes. However, there remain a number of key differences between operations and projects, including the non-routine and temporary nature of project work and the strong change mandate that drives many projects (Reich et al., 2013; Turner \& Mueller, 2003; Williams, 2009). Safety-critical projects also typically progress at a more measured pace, are more loosely coupled and less highly dynamic than an active operational context such as the real-time operating environment of a nuclear power plant.

The study reported on here extends the application of high reliability theory into the domain of the safety-critical project and provides the first empirical evidence for practices associated with high reliability organising in safety-critical projects as a response to project uncertainty. We draw on 47 retrospective accounts (vignettes) of project uncertainty from project management practitioners on nine safety-critical projects to investigate the following research question: 
"How does the manner in which project management practitioners respond to uncertain situations compare with the principles of an ideal-type high-reliability organisation?"

Our contribution to theory is twofold. First, we empirically examine whether practices consistent with high reliability organising are adopted by project management practitioners in safety-critical projects in response to uncertain situations. Secondly, we provide the first empirical testing of earlier work by (Saunders, 2015), who posited the principles of an ideal-type high-reliability organisation and the notion of high reliability project organising . This approach is consistent with Reich et al.'s (2013) call for project management research not to reinvent theory, but rather use extant theories from the wider domain of organisational theory as a lens through which to view projects.

Lastly, we did not investigate any causal relationships between evidence for high reliability practices and eventual project outcomes as the nine case-study projects in this study were each at very different stages of their lifecycle, and none were yet complete. One other hypothesis raised by this study is whether interviewing the same respondents at a different (later) point in their projects' lifecycle would yield different results. And, if there is a difference in results, is this a function of the project's lifecycle stage and fact that uncertainty typically decreases as the project proceeds (Winch, 2010), or of the additional experience gained by the respondent during the intervening time. Investigating this hypothesis also lies outside the scope of this paper.

The remainder of the paper proceeds as follows; first, the literature on high reliability organising is discussed and the principles of an ideal-type high-reliability organisation presented. Subsequent sections describe the study design, the findings and explore their implications for both theory and practice.

\section{The theoretical context}

The aim of early research on high reliability organisations (HROs) was to explore how three specific organisations (a nuclear power plant, the US air traffic control network and US navy aircraft carriers (La Porte, 1988; Rochlin et al., 1987; Schulman, 1993) appeared to violate the principles of normal accident theory (Perrow, 1984) - the commonly accepted theory of accidents at the time - and 
managed to maintain safe and reliable operations, while often operating under considerable time pressure in high-risk environments (Rochlin, 2011). The researchers identified several common features in the three organisations including the high prioritisation of safety, decentralised decision making within a strong management hierarchy, the presence of organisational and technical redundancy and powerful cultures of learning, openness and accountability (Roberts \& Bea, 2001). They argued that high reliability organisations are not error free, but rather remain obsessive about the potential causes of failure and are quick to respond to any errors that do occur (Weick, Sutcliffe, \& Obstfeld, 1999; Weick \& Sutcliffe, 2007).

Since the late 1980 's, HRO research has proliferated, leading to an extensive body of work - largely case study based - but latterly attempting to position HROs within the wider domain of organisational theory (cf. Boin \& van Eeten, 2013; Klein, Bigley, \& Roberts, 1995; Mannarelli et al., 1996; Myers, 2005; Ruchlin, 2004). As HRO research has evolved, some of its early assumptions have also been revised. For example, early studies viewed HROs as closed systems immune from external influences and with the total elimination of errors as the overriding organisational goal. Gradually researchers acknowledged that HROs are in fact open systems; subject to the pressures of "aggressive knowledge watchers" (La Porte, 1996, p64) such as regulators and the wider public. HRO's organisational objectives may also be more nuanced; safety is no longer the single overriding concern, with reliability of service and profitability attaining greater significance (Perin, 2005; Rochlin, 1993). Researchers also accept that in complex, highly interdependent systems errors are inevitable (Perrow, 1984; Rijpma, 1997) but what matters is how resilient the organisation is in predicting, handling and recovering from these errors (Hollnagel, Woods, \& Leveson, 2006).

There are a number of ongoing criticisms of theories of high reliability organising which merit attention. First, there has been a long-running debate between both normal accident theory and high reliability theory as rival explanations of safe performance in safety-critical environments (cf. (Hopkins, 2014; Leveson, Dulac, Marais, \& Carroll, 2009; Rijpma, 1997). Normal Accident Theory contends that the highly-complex and tightly inter-coupled nature of complex socio-technological industrial systems such as nuclear power plants, makes accidents inevitable and to be expected. 
Sagan (1993) argues that NAT takes a pessimistic view; asserting that accidents are inevitable and that adding redundancy to systems can actually increase the interactive complexity that can lead to accidents. In contrast, high reliability organising is more optimistic, implying that accidents can be avoided through effective organisational structures and management, and that redundancy provides the organisational slack to foster safe operation. Secondly, there is an ongoing discussion over whether high reliability theory is still relevant in lower hazard sectors, such as construction or healthcare, where reliability is a relative rather than an absolute requirement (cf. Olde Scholtenhuis \& Doree, 2013). The third point of contention is whether theories of high reliability organising are at all empirically testable; if HROs cannot be identified a priori, then it is impossible to assess whether they actually possess the defining characteristics of HROs (Hopkins, 2014).

Despite these unresolved questions, researchers have widened the application of high reliability theory to several other highly complex and consequential operational environments - for instance: healthcare (Chassin \& Loeb, 2013; Ruchlin, 2004), power generation (Roe, Schulman, van Eeten, \& de Bruijne, 2004; Roe \& Schulman, 2008), oil and gas industry (Mannarelli et al., 1996; Thorogood, 2013), firefighting (Barton et al., 2015; Thomas, Fox, \& Miller, 2015; Vidal \& Roberts, 2014), the military (Bierly \& Spender, 1995; Demchak, 1996) and construction (Busby \& Iszatt-White, 2014; Olde Scholtenhuis \& Doree, 2013). However, there are very few studies that have explored large-scale projects through the lens of high reliability theory and those that have are limited to either IT (Denyer, Kutsch, Lee-Kelley, \& Hall, 2011; Sullivan \& Beach, 2009) or construction projects (Brady \& Davies, 2010; Olde Scholtenhuis \& Doree, 2013). To date, there have been no empirical studies of high reliability organising in the specific context of the safety-critical project (projects where safety is of paramount importance and where the hazards that must be controlled can harm the environment, personnel, or the public (Wears, 2012)). Reiman, Rollenhagen, Pietikäinen, \& Heikkilä (2015) argue that safety-critical projects constitute a distinct project context, as the hazards of nuclear power generation differ greatly in magnitude from the hazards of a typical construction site. 


\subsection{Characteristics of an "ideal-type" high reliability organisation}

A number of authors have sought to characterise HROs (notably Boin \& Schulman, 2008; La Porte, 1996; Roberts \& Rousseau, 1989; Weick et al., 1999; Weick \& Sutcliffe, 2007) . Saunders (2015) synthesised an "ideal-type high reliability organisation" from this literature which comprises five main features: clear organisational objectives, a strong organisational culture, the presence of redundancy and slack, mindful behaviour and the ability to prosper in the paradoxes.

Saunders (2015) then discussed the similarities and differences between safety-critical projects and ongoing operations - arguing that safety-critical projects were sufficiently similar to ongoing operations to permit the translation of theories of high reliability organising to the project context, and generating a number of practices and behaviours that might be observed in high-reliability project organising (see Table 1). Our aim here is to empirically examine whether these practices and behaviours are adopted by project managers as a response to project uncertainty. This approach is consistent with (Barton et al., 2015; Gebauer, 2012; Vidal, 2015; Weick \& Sutcliffe, 2007), who have all argued previously that high reliability thinking, and in particular the principles of mindfulness implicit in it, enables individuals and organisations to better cope with uncertainty. However, we acknowledge that Saunders' (2015) notion of high reliability project organising has much wider applicability than in the management of project uncertainty alone, and may also be relevant to a broader range of project types, but this empirical work lies outside the scope of this paper. 


\begin{tabular}{|c|c|}
\hline $\begin{array}{l}\text { Core HRO } \\
\text { Characteristic }\end{array}$ & High reliability projects might: \\
\hline $\begin{array}{l}\text { Clarity of } \\
\text { Objectives } \\
\text { (A) }\end{array}$ & $\begin{array}{l}\text { 1. Accelerate the formation of a dedicated project organisation with capable project leadership, and } \\
\text { articulate a strong sense of mission in the team. } \\
\text { 2. Make project objectives explicit, articulate them clearly and ensure that the trade-offs are } \\
\text { understood. } \\
\text { 3. Communicate the core events that must be precluded. } \\
\text { 4. Acknowledge high levels of uncertainty early on. Accept work may start on the project with only } \\
\text { minimum agreed high level objectives and many untested assumptions. } \\
\text { 5. Ensure that project documentation, plans and team incentives are consistent with the declared } \\
\text { project objectives. }\end{array}$ \\
\hline $\begin{array}{l}\text { Strong } \\
\text { Organisational } \\
\text { Culture } \\
\text { (B) }\end{array}$ & $\begin{array}{l}\text { 1. Build on prior safety-critical project approaches. It may not be necessary to reinvent the wheel. } \\
\text { Encourage learning in the project team by making time to share individuals' stories, lessons } \\
\text { learnt, past project experiences. } \\
\text { 2. Foster interconnections and relationships that span the project hierarchies and from which } \\
\text { communities of practice may start to emerge. } \\
\text { 3. Signal what is valued in the project by rewarding openness, knowledge sharing, multi- } \\
\text { disciplinary problem solving and allow mistakes to be made and openly reported. } \\
\text { 4. Afford areas of ignorance in the project the same importance as areas of certainty - discussing } \\
\text { and debating them rather than closing them down } \\
\text { 5. Delegate decision making (within pre-agreed decision rules), trust project team members and } \\
\text { allow the sometimes quiet voice of the expert to be privileged above management orthodoxy. } \\
\text { 6. Promote and reward project management capability and culture equally to the } \\
\text { techno/professional one. }\end{array}$ \\
\hline 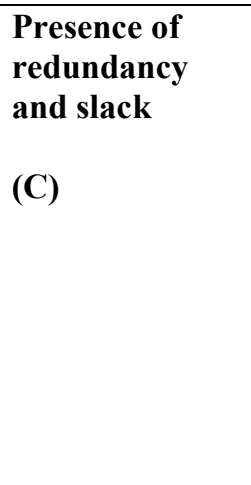 & $\begin{array}{l}\text { 1. Understand the underlying tempo and rhythm of the project. When do key decisions need to be } \\
\text { made, and what is the real level of urgency? } \\
\text { 2. Allow flexible and staged conformance to project processes, casting them off in emergency or } \\
\text { urgent project situations. } \\
\text { 3. Encourage the team to discuss and negotiate their way to a plan of action that is appropriate to } \\
\text { the specific project situation. } \\
\text { 4. Separate responsibility for technical delivery with schedule/cost delivery - Hold the two in } \\
\text { constructive tension. } \\
\text { 5. Make every effort to develop reflective project management practitioners who can think on their } \\
\text { feet and not simply turn the handle of the project processes. } \\
\text { Advocate career progression that depends not only on delivery of project milestones but on } \\
\text { demonstration of the "right" behaviours. }\end{array}$ \\
\hline $\begin{array}{l}\text { Mindfulness } \\
\text { (D) }\end{array}$ & $\begin{array}{l}\text { 1. Avoid complacency. Engage continuously in "what if?" questions and worry constantly about } \\
\text { "what could go wrong here in the project?" } \\
\text { 2. Be attuned to small changes in projects that may be the precursors to bigger issues. } \\
\text { 3. Avoid the tendency to jump to conclusions and make assumptions about the underlying causes of } \\
\text { project problems } \\
\text { 4. Maintain thorough knowledge of the project status, leading project indicators and talk to the } \\
\text { experts on the ground. Treat intuition as importantly as hard project data. } \\
\text { 5. Avoid over-rigid processes, routines and decision making and create space in the project for } \\
\text { reflection, robust debate and even elements of anarchy. }\end{array}$ \\
\hline $\begin{array}{l}\text { Ability to } \\
\text { prosper in the } \\
\text { paradoxes } \\
\text { (E) }\end{array}$ & $\begin{array}{l}\text { 1. Fight to retain flexibility in the proposed project solution even when this may increase project } \\
\text { complexity in the short term. } \\
\text { 2. Involve a more diverse coalition of project actors in project decision making even if this } \\
\text { challenges the existing project consensus. } \\
\text { 3. Acknowledge and articulate the paradoxes inherent in a high reliability project. } \\
\text { 4. Learn that uncertainties in safety-critical projects cannot be eliminated; instead project managers } \\
\text { must be able to dwell comfortably amongst this ambiguity. }\end{array}$ \\
\hline
\end{tabular}

Table 1: Characteristics A1 to E4 about observable practices in "high-reliability project organising" (adapted from Saunders (2015)) 


\section{Methodology and Methods}

The ontology underpinning the study is an objectivist one, which demands that reality is objective and measurable and exists externally to its social actors (Guba \& Lincoln, 1998); and that generated knowledge should be based on observations of this reality (Grix, 2010). To achieve this, we adopted a qualitative research design which utilised semi-structured interviews (Cassell, 2011) to capture detailed accounts of how respondents identified, analysed and acted upon instances of project uncertainty. The study design was informed by extensive reviews of the literature on project uncertainty and theories of high-reliability organising and on the earlier work by Saunders (2015). Interviews were held with 30 project management practitioners involved in nine large safety-critical projects. The projects were selected to reflect two main types: "new build/new product introduction projects" and "maintenance projects" and ranged in size from a three year, circa £35Million budget to a 10-12 year, circa £14Billion budget. None of the projects were yet complete. Each project was located within the UK (with the exception of one aerospace test facility which was located in Germany, but led from the UK) and most encompassed supply chains that were complex and international in nature. Each project was also highly regulated: internally through an independent inhouse regulatory division, and externally by the Office for Nuclear Regulation and the Environment Agency for civil nuclear projects, and the European Aviation Safety Agency, Federal Aviation Authority and other national airworthiness bodies for civil aerospace projects. Individual semistructured interviews (lasting approximately 1 hour) were undertaken at the project sites during 2014 . Several respondents per project were interviewed to minimise individual respondent bias. Respondents were chosen using intensity sampling (as a form of purposeful sampling where respondents are selected who are experts about a particular experience(Morse, 1994,p228)). An anonymised list of the nine projects and the respondent roles is provided in Table 2 below. The projects are coded CA1 to CA4 for the civil aerospace projects and $\mathrm{CN} 1$ to $\mathrm{CN} 5$ for civil nuclear.

During the interviews respondents were asked to recount instances of uncertainty that had arisen during their project. Respondents were free to choose any instance of uncertainty, at any stage of the project lifecycle. 


\begin{tabular}{|l|l|l|l|l|}
\hline Project Description & Code & Industry Sector & Project Type & Respondent Roles \\
\hline $\begin{array}{l}\text { Intermediate level } \\
\text { waste (ILW) storage } \\
\text { facility }\end{array}$ & CN1 & Civil Nuclear & maintenance & $\begin{array}{l}\text { Project Engineering Manager } \\
\text { Project Director } \\
\text { Project Controller } \\
\text { Commercial Manager }\end{array}$ \\
\hline $\begin{array}{l}\text { Reactor life-extension } \\
\text { project }\end{array}$ & CN2 & Civil Nuclear & maintenance & $\begin{array}{l}\text { Group Head of Project } \\
\text { Technical Lead } \\
\text { Sub-project Manager } \\
\text { Sub-project Manager }\end{array}$ \\
\hline $\begin{array}{l}\text { Development of new } \\
\text { civil nuclear test } \\
\text { facilities }\end{array}$ & CN3 & Civil Nuclear & $\begin{array}{l}\text { new build/new product } \\
\text { introduction }\end{array}$ & $\begin{array}{l}\text { Senior Project Manager } \\
\text { Project Manager } \\
\text { Risk Analyst }\end{array}$ \\
\hline $\begin{array}{l}\text { Nuclear new build } \\
\text { project }\end{array}$ & CN4 & Civil Nuclear & $\begin{array}{l}\text { new build/new product } \\
\text { introduction }\end{array}$ & $\begin{array}{l}\text { Programme Manager } \\
\text { Programme Manager } \\
\text { Programme Manager } \\
\text { Programme Manager }\end{array}$ \\
\hline $\begin{array}{l}\text { Decommissioning of } \\
\text { specific elements of } \\
\text { nuclear power station }\end{array}$ & CN5 & Civil Nuclear & maintenance & $\begin{array}{l}\text { Project Manager } \\
\text { Commercial Manager } \\
\text { Client account director }\end{array}$ \\
\hline $\begin{array}{l}\text { Development of major } \\
\text { component of new } \\
\text { wide bodied airliner }\end{array}$ & CA1 & Civil Aerospace & $\begin{array}{l}\text { new build/new product } \\
\text { introduction }\end{array}$ & $\begin{array}{l}\text { Subsystem Programme } \\
\text { Manager } \\
\text { Subsystem Programme } \\
\text { Manager } \\
\text { Deputy Programme Executive }\end{array}$ \\
\hline $\begin{array}{l}\text { Retrofit of safety- } \\
\text { critical assemblies to } \\
\text { in-service aircraft }\end{array}$ & CA2 & Civil Aerospace & maintenance & $\begin{array}{l}\text { In service Programme manager } \\
\text { Operations Shift Manager } \\
\text { Project Team Leader }\end{array}$ \\
\hline $\begin{array}{l}\text { Phased upgrades to in- } \\
\text { service aircraft }\end{array}$ & CA3 & Civil Aerospace \\
test facility
\end{tabular}

Table 2: Case study projects and respondent roles

\section{Part Two}

I'd like you to recall 2 instances of project uncertainty that have occurred on this project. Please would you talk me through these incidents.

- How did the uncertainty emerge?

- How was the uncertainty identified?

- Who were the main actors and what did they do?

- How was the uncertainty analysed and interpreted?

- What action was taken?

- What was the outcome of this incident of uncertainty on the project?

Figure 1: Interview protocol 
The interview prompts (Figure 1) were based on Daft \& Weick's (1984) theory of the organisation as an interpretive system and explored how the uncertainty had arisen, was acted upon and what its impact on the project was. To avoid leading respondents, the researchers made no mention of high reliability theory. Instead respondents recounted these vignettes of project uncertainty in their own words, producing rich, if subjective, retrospective recollections of the practices and behaviours that were adopted as a response to project uncertainty. In total, 47 vignettes of project uncertainty were described; 23 from aerospace and 24 from nuclear projects. Vignettes covered a range of emerging uncertainties, from the discovery of an oil leak in an aircraft gearbox, uncertainty over the choice of technology to use in a nuclear transfer flask, to uncertainty in the proposed organisational structure for a nuclear new build project.

The interview transcripts were uploaded into NVivo10. Using NVivo to support qualitative data analysis can improve data management, the transparency of the analysis and increase the flexibility of the analysis process (Crowley, Harré, \& Tagg, 2002; Gibbs, 2014). However, there is a risk that NVivo can shape the analysis and that using software can alienate the researcher team from the data. In this study the software only provided organisational support for the analysis and no internal NVivo software rules were used to impose interpretations on the data. A technique called template analysis was used to analyse the transcripts. Template analysis involves the use of a coding template which is generated either a priori or from a preliminary analysis of a subset of the data (Brooks, McCluskey, Turley, \& King, 2015). The coding structure in this study was a priori identified and comprised characteristics A1 to E4 of high reliability project organising as posited by Saunders (2015). This coding structure as it appeared in NVivo 10 is shown in Figure 2 below.

Each vignette was coded according to the template in Figure 2, by reading through the vignette looking for evidence for practices either consistent or at odds with each characteristic. King ( 2004) warns against the counting of the frequency of occurrence of each code in template analysis; as one cannot assume that the frequency of occurrence of a code represents its salience. Instead the distribution of codes across respondents and projects merely suggests avenues for further investigation. 


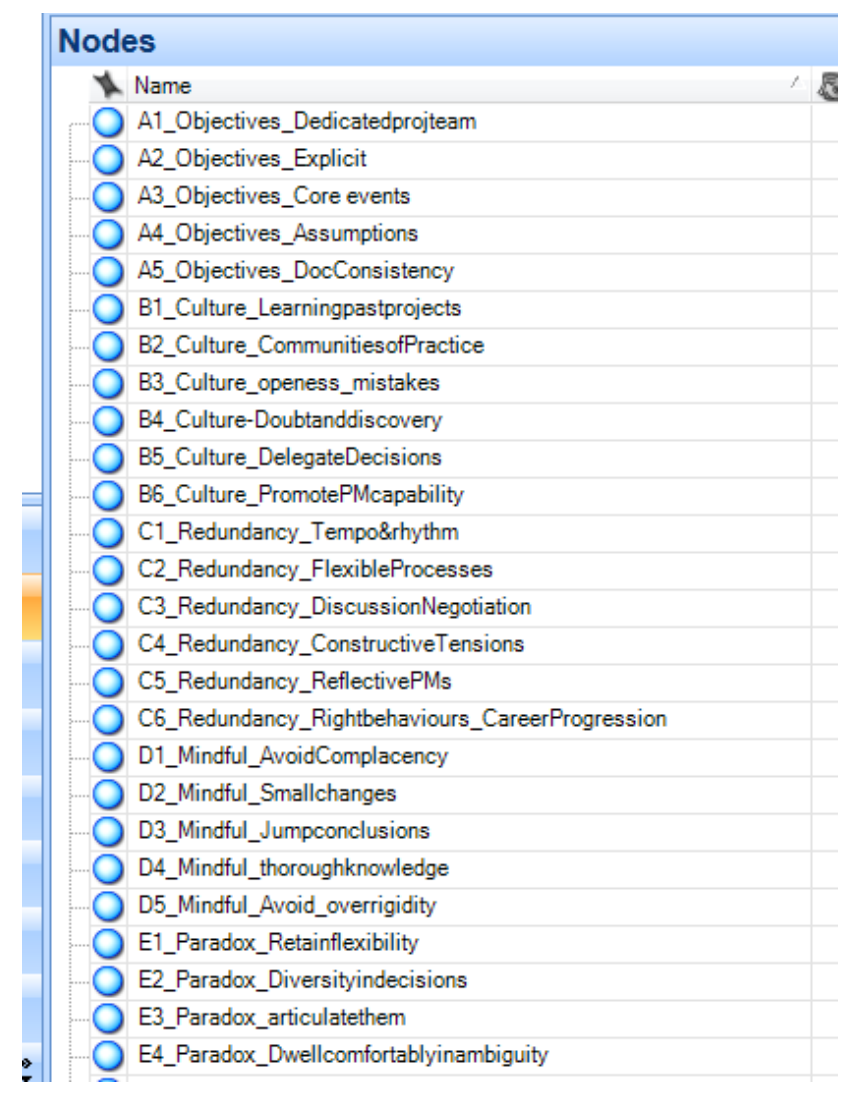

Figure 2: Coding template for evidence for high reliability practices as a response to project uncertainty

\section{Findings}

The findings are organised around the 5 features of an ideal-type high reliability organisation and the associated principles of high reliability project organising posited by Saunders (2015). Within each section we have also highlighted areas of commonality and difference between the two sectors, and areas of alignment and dissonance with theories of high reliability organising, the implications of which we return to in the later discussion.

\subsection{Clarity of Objectives}

In both sectors the projects were organised as dedicated project teams in line with characteristic A1; the size, priority and consequential nature of the projects made this an essential prerequisite. These teams were multi-layered with core programme delivery teams supplemented with a number of temporary work package specific teams, tasked with designing and delivering a particular aerospace 
subsystem, or planning the optimal sequence of installing services into different areas of a new nuclear power station. Instilling the right values and behaviours in each of these dispersed and disparate teams was not without challenge, as demonstrated by this quotation from a civil nuclear programme manager.

"There has been a great deal of effort put in to try to shape the structure, and make it a normal delivery organisation. We have made some progress. We inherited from [Organisation X] a structure which was based on contracts. You can't do a project like this. It's not just about contracts. It's about the interfaces and gaps between the contracts that are the problem. It's taken us a long time to shift away from this, to say we are going to manage by areas"

Several respondents also discussed the need to work with assumptions when responding to uncertainty, often well into the detailed design phase - providing evidence for characteristic A4. For example in developing new nuclear test facilities $(\mathrm{CN} 3)$ a respondent spoke of

"There are too many unknowns in the project. We are working up the delivery brief. The project hasn't been given a definitive 'you shall do this, with this, at this time'. We are defining our own scope of delivery."

Faced with this situation, the projects proceeded cautiously and systematically, working with assumptions and drawing on all the expertise that was available (both within and beyond the project organisation) to try to reduce the uncertainties and consequent risks to project delivery. However there were some key differences between the sectors; with civil nuclear projects exhibiting a stronger sense of mission (characteristic A1), more acknowledgement of the trade-offs across performance objectives (A2) and of the core events that must be precluded from happening (A3). For example, when the objectives and delivery mechanism for a new Intermediate Level Waste (ILW) storage facility (CN1) were suddenly changed this created a high level of uncertainty. The team worked hard to define the new objectives and garner a renewed sense of mission in the projectdespite initially feeling frustrated by these upheavals in a project in which considerable emotional effort had been expended. On the same project the trade-offs in project priorities were openly stated, with the intention of encouraging desired project behaviours, for example by deliberately not 
specifying a due by date in the contract bid process. Civil nuclear respondents also recounted several examples of events that were not permitted under any circumstances such as failure to produce a safety case on time, or operating a nuclear power station outside the limits prescribed by the safety case. For example, during routine sampling within the graphite core of a nuclear power plant (CN2) higher than expected weight-loss was encountered, requiring the rapid writing of an emergency safety-case, without which the reactor would have been shut-down.

In civil aerospace, this clarity of objectives, whilst in evidence at the programme manager level, did not always permeate all areas and levels of the projects, as articulated by the following civil aerospace respondent:

"the impact it has on uncertainty is that the people doing the work did not know that if the [new subsystem] had got on the aircraft we would have been stuck with it for a very long time, demolishing our salaries on a monthly basis"

Another common concern, almost preoccupation, amongst civil aerospace respondents was that of securing resources, and the challenge of keeping specialist resources tethered to the project team. There were several examples of projects starting despite key resources still being fully utilised on other projects, and of organisational restructuring and frequent personnel changes impacting the project's sense of mission. Although the project teams were aware of this weakness in the organisational environment of the project, they were powerless to change it; evidence of the fragility of high reliability project organising.

\subsection{Strong Organisational Culture}

Both sectors provided evidence of learning (B1), of taking visible actions that reward openness and knowledge sharing (B3) and of delegated decision making (B5).

"At the end of day knowledge, skills, experience and wisdom are engendered in the people in the team. We learn. We become more competent individuals. So learning is shared with programme and stakeholders - done consciously." Civil nuclear respondent "I've come from [x] programme and now work on [y] so I can share my experience with the new team. We do have lessons learnt logs and we typically do this at the end of each phase so I am about 
to do this for the current phase. I will look at what we did on the [x] programme and did we carry any mistakes into the [y] programme and I'll put processes and procedures in place to make sure that doesn't happen again. "'Civil aerospace respondent

Learning on projects in both sectors was deliberate. This learning was often codified (in the form of revised processes, or a lessons learnt log) and communicated to others to allow the lessons to be acted on throughout the project team. Overall learning was more formal within civil nuclear projects, with respondents being more likely to document learning from past projects and draw on those lessons learnt logs and revised processes. In contrast learning in the civil aerospace projects was often based on relationships, and knowing the right person to ask in a given situation - evidence of two contrasting learning strategies - codification vs personalisation - in the two sectors (Hansen, Nohria, \& Tierney, 1999).

Openness and knowledge sharing (B3) as a response to project uncertainty was evidenced in both sectors as exemplified on the nuclear life extension project (CN2) below:

"Prioritisation of tasks is done with the safety case officer but it's not an authoritarian approach. It is more about openness with partners. We work better when we are more open. Whenever a question is raised I try to make sure whoever has asked the question is satisfied with the answer."

The ILW storage facility project (CN1) provided further evidence of this desire to signal what is valued in the project and the sanctioning of a more collaborative style of working rather than a culture of blame.

"For example we have to hold ourselves to account for time periods and also hold the contractors to account. If either side is going to fail we need to raise an early warning and work together with mutual trust and respect and co-operation to try to deliver a successful outcome. We need to be a much better client. This is totally alien to company culture."

In both sectors the ability to nurture a high reliability project culture of openness seemed to rely more on the interpersonal skills and sheer force of will of senior project staff, rather than being mandated by the host project organisation. The challenge facing respondents was how to encourage and nurture 
this culture of openness, within a prevailing organisational culture that would often prefer not to "admit to problems in capacity in the supply chain. So approach is that we will just muddle through the project and project timescale will just start to slip to the right." (Civil nuclear respondent) Again this is evidence of the fragile nature of the high reliability project organisation.

Individuals, including those outside the core project organisation, were also generally empowered to discuss and make technical decisions (B5) in response to project uncertainty as articulated here:

"We got the people who were involved at the time, who were the experts in the design, as the [component] suite is contracted out to external third parties on a design and make basis. They are the experts in this technology, not us. " Civil aerospace respondent This privileging of technical experts was widely encountered across both civil nuclear and aerospace projects. Perhaps due to the complexity of the technology, the project management practitioners regularly sought out the organisation's key technical specialist to understand a problem, better quantify the risks associated with different courses of action and for reassurance that nothing had been missed. The challenge facing especially the civil nuclear industry is the impending retirement of large sections of the technical nuclear community (Cogent, 2009; Kettunen, Reiman, \& Wahlström, 2007) and the subsequent loss in expertise. This is a further illustration of the fragility of high-reliability project organising, which depends on deep and often tacit technical knowledge, which will one day be lost to the organisation.

A key difference between the two sectors was in their willingness to afford areas of ignorance in the project the same importance as areas of certainty (B4). Several civil nuclear respondents provided examples of attempts to bring uncertainty out into the open, whereas there was limited evidence of this within civil aerospace. Civil nuclear respondents recognised that the first step in resolving uncertainty is to know where it resides, whether in the interfaces between contracts or technical specialists, or in the robustness of the base-lined project schedule as recounted by a nuclear respondent 
"What creates uncertainty is the failure to have a nice base-lined project. The approach to the schedule here is not the approach that I am used to. ..... Here a lot of it is coming from the Responsible Designer saying 'here is what we think we are doing'. So no one knows how long it is going to take. "

The project managers who were able to afford areas of ignorance the same or even greater priority than areas of certainty were lone voices at first in this project, but by working closely together and demonstrating small successes, they gradually engendered a noticeable cultural shift in the wider organisation.

"Us as a small group of programme managers, we directly influenced the way the organisation is shaping itself and the level of rigour that is in the cost and the schedule plan."

Civil nuclear respondent

Lastly, there was limited evidence in either sector of projects fostering interconnections that spanned project hierarchies (B2) or of rewarding project management capability and culture equally to techno/professional capability (B6). Nevertheless, there was an acknowledgement that core project teams and senior individuals within those teams had a responsibility to lead by example, encouraging the right behaviours early in the project delivery to avoid the confrontations that are often associated with managing contractors. In the nuclear sector an early contract was repeatedly delayed and its scope amended until the contract was no longer fit for purpose. Faced with a contract whose commercial arrangements were well adrift from the project objectives, the programme manager chose to terminate the contract for the following reason

"and being the first contract, is this giving us the behaviours that we want to see on the project?” Civil nuclear respondent

There were also instances of close, collaborative working with respondents building strong relationships, which helped resolve the tensions, trade-offs and inherent complexities of large-scale safety-critical projects.

"We are a multifunctional team and I work with two colleagues - one supply chain chap and one engineering chap. We spend a lot of time together..... Our aim is as many engines on test as quickly as possible - execute certain experiments and learn as much as we can. The 
design is invariably late. Once we have the design we then struggle to get the parts in the door....We are constantly looking at the picture of variables that is driving the test programme - can we do this or that to maximise our learning? " Civil aerospace respondent

\subsection{Presence of Redundancy and Slack}

Both sectors provided evidence of projects allowing flexible and staged conformance to project processes (C1), of encouraging the team to negotiate their way to a situation specific plan of action (C3) and of the development of reflective project management practitioners (C5).

Within nuclear, flexible conformance to project processes was shown on the ILW storage facility (CN1), where the levels of estimating uncertainty were high, due to the absence of norms for the required work scope. In response a conscious decision was made to prepare initial estimates with higher levels of uncertainty than those organisationally mandated.

"This is new. Systems are not configured to allow this and approaches and procedures do not support it. So those are the challenges we face. Its obvious procedures don't work, systems do not support, so often flying on systems that are being pulled together as we go".

The Project Director had to tenaciously argue her case here with the project's sponsors, a brave step in a project closely monitored by the regulatory authorities and the UK National Audit Office.

In civil aerospace, the established rhythm of the development programme could quickly alter accompanied by rapid escalation and prioritisation of tasks, as this case of a new subsystem being unfit for purpose for an aircraft engine shows.

"I actually quite like it when the choice is clear-absolutely knackered or fix it now-easy decision - priority calls are easy to make, budget is available - go straight to top with no endless approvals required." Civil aerospace respondent

Although the project was initially slow to realise the issues with the subsystem, once alerted to the seriousness of the situation the project cast off the established processes and rapidly developed a second solution in parallel with the first, to enable a quick switch-over to happen.

Many respondents across both sectors also described instances of project uncertainty where discussion and negotiation lay at the heart of the analysis process (C3). These discussions were always multi- 
functional in nature and usually included supply chain and customer representatives. The following quotation from the subsystem retrofit project (CA2) illustrates this.

"There are a couple of turning points in all of this. We had a workshop January this year and we've had various meetings but as things got closer we were more confident that the design would pass qualification the urgency to get these things resolved rose. Some of the assumptions that were in the plan on day one needed to be revisited."

Further evidence of $\mathrm{C} 3$ was demonstrated in how the same project organised the roll-out of the retrofit parts, building in redundancy to the process so that the system as a whole became more reliable. This allowed different airline operators to work at different retrofit rates and evidenced a preference for a system wide solution rather than a project focused solution.

Evidence of the emergence of reflective practitioners (C5) was found in both sectors too, although there were more examples of it amongst civil nuclear respondents. For example one nuclear programme management team reflected at length on how to implement a more robust contractor engagement process within a conservative, contractually driven technical organisation.

"The idea of the ECI [Early Contractor Involvement] was a little bit organic. We did some work with the civils and that was the starter. As time went on it became clear that such an approach could have wider benefits and this is how the strategy emerged. We started in civils and we have expanded this approach across all the disciplines and I would look to take this approach into future projects. It's a very good tool. I probably wouldn't have thought of by myself - I am not sure any of us would in isolation." Civil nuclear respondent

These findings echo those of the civil aerospace projects in that, at least at the higher echelons of the management of safety-critical projects, practitioners are thoughtful and reflective, rather than trained technicians adept at turning the handle of well-documented project processes as argued by Crawford, Morris, Thomas, \& Winter (2006).

There were areas of dissonance between the sectors in terms of understanding the underlying tempo and rhythm of the project (C2) and for separating responsibility for technical delivery from schedule/cost delivery (C4). Civil nuclear projects demonstrated less emphasis on time and tempo 
(C2) than the rapid drum beat of the civil aerospace product development programmes, driven by entry into service dates. Even on the in-service nuclear plant (CN2) there was rarely a sense of urgency, with the project team working steadily towards the next safety-case. In civil aerospace the following quotation demonstrates that the way project uncertainties are managed is dependent on their nature and their speed of change.

"I guess it's about pace of change - my job changes by the hour as I'm trying to execute an engine build. This market stuff - does it change monthly? No. Does it change year to year? Probably so I review it more infrequently." Civil aerospace respondent In contrast, there was much clearer separation of responsibility for technical delivery with schedule/cost delivery $(\mathrm{C} 4)$ in nuclear projects than in aerospace. Interestingly, this tension was not viewed negatively, but rather as an effective means of maintaining conceptual slack in the organisation. For example

"There is tension in the relationship between the technical and the project management guys but this is positive and encouraged as it provides multiple perspectives and diversity of opinion." Civil nuclear respondent

Further evidence of this constructive tension was provided on (CN3) with one respondent commenting that

"This is a really good bunch of people I work with. They fight and they bicker but at the end of the day they all work very hard together, to get the project delivered."

Another dimension to this tension was that between nuclear and non-nuclear professionals, who had different experiences of project delivery environments. For instance, there has been a transfer of project managers into nuclear new build from other recently completed infrastructure projects (Davies \& Mackenzie, 2014). On CN4, this tension was evident as the 'non-nuclear 'programme managers sought to reduce the construction schedule duration by undertaking a number of activities in parallel with one another, a change strongly resisted by the 'nuclear' project managers.

\subsection{Mindfulness}


Whilst this study found evidence for all the posited practices associated with mindfulness (D1-D5) in response to project uncertainty, there were commonalities and noticeable differences across the two sectors. In both sectors respondents stressed the importance of not jumping to conclusions (D3) and maintained a thorough knowledge of the project status (D4). However there was stronger evidence in nuclear projects for avoiding complacency (D1) and being attuned to small changes in projects (D2) and more evidence for avoiding over-rigid processes (D5) within civil aerospace.

Respondents in both sectors emphasised the need to understand what they did not know, and the effectiveness of simple questioning to help uncover the actual status of specific issues and increase their confidence in the available data. Respondents focused on the root causes of issues, avoiding jumping to possibly erroneous conclusions as shown here:

"The issue emerged on a routine maintenance check that was done. That flight was then grounded and the units were stripped off and sent back to us for investigation. When we investigated it there was no fault found because it was as per the drawing but when we investigated further and took the cap off we noticed a reservoir of liquid." Civil aerospace respondent

Respondents also described making judgement calls, assessing priorities and knowing when to escalate uncertain situations to senior management as shown here:

"My role is to quantify and put enough value and structure in place to deal with that risk, and questioning, probing the teams to make sure that they have taken these actions both in the commercial teams and in the technical teams. I do that through experience and asking the right questions in reviews." Civil nuclear respondent "Sometimes it is gut-feel and instinct, and you just get a feel for those are the three or four things I need to make sure are supported, coaxed along. The rest of the stuff will just happen." Civil aerospace respondent

Individuals in both sectors utilised a range of approaches, e.g. active questioning, formal status reports, regular meetings, and relied on a combination of hard data and intuition (often based on extensive past experience) to process detailed information and act on it. This raises two challenges 
for highly consequential safety-critical projects: how to avoid biased decision making (Gladwell, 2006; Tversky \& Kahneman, 1982) when relying on intuition and judgement?, and how well equipped are these project management practitioners to anticipate and react to Black Swan events those that lie well beyond their span of experience? (Taleb, 2007)

No instances of complacency in nuclear projects were recounted (D1). Instead nuclear respondents seemed to share a nagging sense of what might go wrong on these highly-consequential projects and described "sniffing out uncertainty by feeling my way, and trying to understand what I do not know" and "starting any project with a heightened level of nervousness, nervous energy almost, because you want to shake things and reduce the risks and uncertainties". Experienced individuals had often been caught out on previous projects and consequently operated with an amplified awareness of what could go wrong. The picture in civil aerospace was more nuanced. On occasion, complacency manifested itself in the initial denial of issues. At other times, suppliers were not challenged on the robustness of their project schedules, as described by one respondent on the engine test facility (CA4)

“We've used them [supplier Z] before ....... Out there we did have a similar situation but we managed to sit down with [supplier Z], to get them to understand that they were a month behind, and they held programme from that point onwards. That gave us a false sense of security, in terms of this particular project."

In contrast, another civil aerospace respondent had drawn up a Plan B approach, only to be unable to gain traction from the wider project organisation to resolve the issue.

"So we are now in limbo waiting for this software test to be done. So this is all very uncomfortable now as it may end up being a major issue, in which case we will come under pressure to do a modification very quickly.... And we are still sitting here waiting around and it just doesn't feel quite right. Personally I think we should be doing some work now at small expense to develop the longer term solution to a certain level of maturity to give us a head start. The problem is the solutions don't fit within my subsystem, and nobody in the other functional areas is working on solving the problem" 
Similarly, there was stronger evidence in civil nuclear for being attuned to small changes in projects that might presage more serious issues (D2). There were examples in both sectors where respondents did view small problems as warning signals of larger issues; or who double checked with the technical experts before proceeding with a technical solution. For example:

"Yes being candid with you we've had a couple of incidents on site recently, where something isn't quite right, not big issues but they are sort of indicators of things we need to nail quickly" Civil nuclear respondent

However, mindfulness seemed a more elusive characteristic in civil aerospace projects; its existence often threatened by schedule pressure caused by aggressive Entry to Service dates which had been pre- agreed with customers. For example:

"So a few months back we had some issues. We had been running development engines, and on strip-down we found some debris in a certain part of the engine...At the time we put it down to development, may be during the manufacturing process some bits had been left behind. Subsequently we found a cracked [component] in another development engine, no debris and the crack was in a slightly different location, and we decided this was a manufacturing defect. We never really connected these two issues together. "'

Contrastingly, in civil aerospace projects there was more evidence for avoiding over-rigid processes in projects (D5). Within civil nuclear projects structures and processes were rigid, informed by onerous regulatory regimes and the conservative nature of the industry as argued by (Oedewald \& Gotcheva, 2015) and (Saunders, Gale, \& Sherry, 2015). There was only one instance of a project being structured more flexibly, as evidenced here:

"We know what we want to do and when, but should new information emerge in the future, or the existing experimental plan is not delivering the data you want then you might have to revisit what you are doing, alter the plan, engage with people, do an independent review and get buy-in." Civil nuclear respondent.

Paradoxically, within the civil aerospace projects, the complexity and turbulence of the engine development programme necessitated more flexible processes. Without this flexibility and rapid 
recalculating and re-planning it would have been impossible to maintain the pace of progress on the engine development programme, maximizing the learning and increasing the maturity of the engine design as quickly as possible.

\subsection{Ability to Prosper in the Paradoxes}

There was widespread evidence for projects in both sectors involving a more diverse coalition of individuals in project decision making (E2) and being able to deal with ambiguity (E4).

Broad coalitions of decision making (E2) were reported on all nine case study projects, with a wide range of experiences and technical specialisms accessed in order to resolve uncertain situations. This coalition of experts was not confined to the host project organisation but was consciously cultivated within the wider supply chain.

For example, the new test facility project (CA4) recounted how expertise from ever widening circles of the supplier base was sought to resolve the challenge of transporting very large aircraft assemblies along the road network in Germany.

"So they [our global physical logistics] came back with this information that we can't get through the bridges in Germany. So at that point we realised we had to engage with logistics professionals in Germany. So the [company Y] Germany team then engaged with some haulage companies out there to get them to look at, and understand the options that we had." Civil aerospace respondent

Similar strong evidence for an ability to deal with ambiguity and be prepared for new uncertainties to emerge (E4) was noted across both sectors, as exemplified below:

"I live with uncertainty. I know the [safety] cases are not lacking in uncertainty. I live with thatI am aware it is there and I openly introduce margin into the safety cases. I try to get one big margin or contingency on top of the safety case. I am happy that that process is happening and that's how I can live with it. " Civil nuclear respondent

"One of the key characteristics of the role is the ability to deal with ambiguity and uncertainty. The reality is that week in week out there will be uncertainty arising. My engineering background 
means I like to know everything that there is to know about something. Over time I've got more comfortable with dealing with uncertainty." Civil aerospace respondent

Central to dealing with project uncertainty was the ability to balance the inevitable tension between being in complete possession of the necessary technical information and the need to drive progress on the project. Many respondents had learnt, often painfully, through past experience never to assume anything, to foster an attitude attuned to the presence of uncertainty, and to adopt a "risk mind-set" that went beyond merely attending to the project risk log.

However this study provided scant evidence of project management practitioners acknowledging and articulating the paradoxes in a high reliability project (E3). There were a couple of exceptions to this, most notably the following quotation:

"I'm pretty convinced now, that uncertainty is a perception. By putting risk and opportunities and assumptions around it, it becomes more concrete and although there is still probability around it. You have to try and put a process around it and try to quantify it. The quantification is itself uncertain because you've got probabilities around it. But at least it's a structured process." Civil nuclear respondent

Here, the individual, on whose shoulders the responsibility for project delivery rests, must satisfy the demands of project sponsors to quantify the level of uncertainty which resides in different elements of the project. Paradoxically, this process, however well-structured and intentioned it is, remains a highly subjective one, influenced by individual experiences, preconceptions and judgements.

Lastly, there was more evidence for projects sanctioning more flexible decision making structures and fighting to retain flexibility in the proposed project solution (E1) in civil nuclear than civil aerospace. For example, this quotation shows how the finding of optimal delivery mechanisms was prioritised over short term project progress on $\mathrm{CN} 1$.

"So we have looked around and found out that Nuclear Decommissioning Authority have these NEC 3 based tools and contract management plans, but they have just not been brought to [Organisation A] site. So we have said we will be the pilot for [Organisation A]. We are 
building a contract management plan and will try to coach the contractor with our contract and our rules of engagement with people on the ground. We will walk them through what has to be delivered, what the constraints are, in first couple of weeks of the contract. So we are trying to look forward as early in the contract as possible to try to anticipate issues, risks and uncertainties. "

Throughout this interview there was a real sense of an individual grappling with paradox; with the project being delivered very differently to previous projects, requiring flexibility and adaptation in hitherto rigid project processes. The Project Director has brought in external staff from a diverse range of backgrounds and experiences and strives to provide the leadership to hold fast to this course, even when issues and difficulties arise.

\section{Discussion}

This study has provided empirical evidence for the adoption of high reliability practices as a response to uncertain situations in large-scale safety-critical projects. Respondents expressed a sense of balancing and juggling in the paradox, for example, in knowing whether to test new engines for flight or run further experiments; and provided evidence of learning, acting mindfully, avoiding over-rigid processes, and of upholding constructive tensions, conceptual slack and close interdisciplinary working.

However these practices were often fragile, with much depending on the tenacity and strength of will of individual project managers, rather than being embedded in the organisation's culture and memory (Schatzki, 2006). Perin (2005) calls for a culture of doubt and discovery as opposed to an all knowing command and control philosophy in these safety-critical environments. The indications of this study are that this culture of doubt and discovery relies heavily on the presence and practices of key individuals, rather than being established throughout project organisation. The challenge facing safety-critical projects is how to identify, develop and nurture sufficient numbers of such individuals who can begin to change the organisation's long established ways of working. 
High reliability practices in this study also often emerged in response to situation specific difficulties as argued by Barton et al. (2015) as opposed to being planned for from the start, and occurred at the project operational level, rather than being mandated by senior management. Another practical implication of this study is the need to increase senior management awareness of the principles of high reliability project organising.

Lastly, high reliability practices in dealing with uncertainty were often local to particular organisational structures and individuals, and were hard to influence beyond the core project team. Structural factors in both civil nuclear and aerospace often thwarted attempts by project managers to act in a manner more consistent with theories of high-reliability project organising. For example, complex ownership structures, the quasi public-sector nature, and short term incentive mechanisms in the civil nuclear industry can tempt organisations to adopt short-term financially expedient project solutions. Oedewald \& Gotcheva (2015) also argue that it is difficult to delegate decision making in large nuclear projects as they are typically structured around long and often fragmented networks of contractors and subcontractors, not all of whom have specific nuclear industry expertise. And in civil aerospace, the commercial imperative to deliver safe engines to tight customer deadlines, can lead to suboptimal resource allocation, reactive responses to emerging problems and a pervasive organisational culture of firefighting. These are structural issues that reside beyond the sphere of influence of even the largest, most consequential safety-critical project.

This study also identified a number of sectoral differences between civil aerospace and nuclear projects. There was more evidence of practices associated with high reliability project organising in civil nuclear projects particularly in terms of characteristics A1,A2 and A3 (having a stronger sense of mission, clearer objectives and core events that had to be precluded), characteristics B3 and B4 (reporting mistakes openly and affording areas of ignorance in the project the same importance as areas of certainty), C4 ( better separation between technical and cost delivery), and D1 and D2 (no evidence of complacency and being attuned to small changes that could be the precursors to something bigger). In civil aerospace projects there was considerably more emphasis on the tempo of projects (C1), and on avoiding over rigid processes (D5). There was virtually no evidence of 
practices at odds with high reliability thinking in civil nuclear. This differed from civil aerospace, where there were several instances where objectives were not clearly communicated, of complacency and slow initial reactions to emerging uncertainties. There are two alternative explanations for this. First, that the requirement for safety in nuclear is so absolute that technology has to be "right first time, every time", even if that means significant delays to a project. And secondly, that the high levels of secrecy and the need to be seen to be in control at all times in the nuclear industry, render any practices at odds with high reliability hidden and beyond the pale. This stands in stark contrast to civil aerospace where projects are driven by ambitious and highly public product launch dates, and development is a more iterative process, with more tolerance of errors and ultimately the assembly, engine or aircraft technology only has to be ultra-safe when it is ready to be certified and to fly.

There are a number of wider theoretical and practical implications of this study. Firstly, there is a risk that high reliability project organisations are viewed as somehow 'heroic'; embodying cultures and cognitive processes that enable high reliability projects to outperform non-high reliability projects (Saunders, 2015). This study has provided no empirical evidence of this. In any case there remain difficulties in defining what is meant by 'high reliability' (Schulman, 1993). Reliability in high reliability organisations has become a proxy for organisational effectiveness, but organisational effectiveness is another problematic construct. What is organisational effectiveness? From whose perspective is it being measured? For all the research into high reliability organisations, and the plethora of defining features for such organisations, high reliability remains subjective; an organisational attribute rather than an objective measure of performance. Additionally the majority of the research on high reliability organising has been descriptive in nature, based on case studies of particular organisational contexts. There has not yet been clear articulation of the mechanism by which the characteristics and processes of high reliability organisations translate into safe and reliable performance (Boin \& Schulman, 2008). For example, which are the most important high reliability characteristics? How do these characteristics translate into effective and safe performance? Although attempts have been made to situate HRO theory within mainstream organisational theory (Creed, 
Stout, \& Roberts, 1993), a significant gap for both research and practice remains an overarching theoretical framework that would provide explanatory power to the principles of HROs.

Secondly, an important issue raised by this study is the transferability of prior high reliability organising research from the operational context into projects. We agree with Sullivan \& Beach (2009) and Saunders (2015) that projects are particular forms of organisations in which the theories of high reliability organising might usefully be applied. Safety-critical projects do share many similarities with ongoing operations, notably their complexity, consequential nature, the presence of uncertainty and the marshalling of many specialist resources to enact organisational processes to deliver a set of objectives. However there are a number of differences between operations and projects, including the more measured tempo at which projects proceed and the temporary and nonroutine nature of the work (c.f. Lundin \& Soderholm, 1995; Reich et al., 2013; Turner \& Mueller, 2003). Finally, Schatzki (2006) contends that a key influence on organisational action is its sense of memory of practices and structures that have served it previously and this memory may simply not be present in a newly forged project organisation. We argue that the long term nature of large-scale safety-critical projects and the regular transfer of individuals from one project to the next enable Schatzki's (2006) organisational memory to be sufficiently preserved from one project to the next.

Finally, some might argue that the evidence for high reliability project organising in this study is simply a response to project organising, rather than being a specific response to project uncertainty. For example, learning from past projects, clarity of objectives and close interdisciplinary working are central to all aspects of project organising. In theory this is true, but as the litany of past failed projects attests, good project management practice is not always adhered to. The contribution of this study is to look at specific instances of uncertainty in highly consequential safety-critical projects, as recounted by those involved, to look for evidence of high reliability practices as a direct response to these uncertainties. We acknowledge that there is an overlap between specific responses to uncertainty and the broader issue of how a project is organised, and in this regard our findings that many practices in safety-critical projects are consistent with high reliability project organising are 
perhaps not so astounding. However, we contend that the highly- consequential nature of large scale safety-critical projects and the imperative attached to their safe execution, render the practices of high reliability project organising essential to the management of project uncertainty, even if that comes at the increased cost and effort of providing redundancy and conceptual slack and of maintaining a razor sharp clarity of focus on safety over other performance objectives.

\section{Conclusions}

This paper makes contributions to both theory and practice in the domain of large-scale safety-critical projects. Theoretically, the paper extends the application of high reliability theory into a new domain (that of the safety-critical project). Secondly, it provides the first empirical examination of how practices associated with high reliability project organising are adopted by project management practitioners in safety-critical projects in response to uncertain situations. In terms of practice, it proffers practices and behaviours that project managers can adopt as a response to project uncertainty and describes the differences between civil nuclear and aerospace sectors in a manner from which practitioners can usefully learn.

The 47 vignettes provide evidence of many practices in safety-critical projects that are consistent with high reliability organising. Respondents expressed a sense of balancing and juggling in the paradox, of learning, acting mindfully, avoiding over-rigid processes, and of upholding constructive tensions, conceptual slack and close interdisciplinary working. There was also more evidence of practices associated with high reliability organising in civil nuclear projects than in civil aerospace projects. However these practices across both sectors were often fragile, less deeply embedded within the host project organisation than proponents of high reliability theory might wish for.

The main limitation in the study is the "snap-shot" nature of the data collection. Despite this, the wide variety of vignettes that were recounted, across projects at several different stages of their lifecycle, has provided sufficient data to assess whether practices consistent with high reliability organising are adopted as a response to project uncertainty in safety-critical projects. Future work will include a return to the projects to complete a longitudinal study of how high reliability project 
organising might evolve over the lifecycle of the projects. For example, will project routines and practices become more rigid and less flexible as the project progresses, and will projects in the later stages become more akin to operations than those at the project front end definition phase and what are the implications of this for high reliability organising? An ongoing longitudinal study would enable these questions to begin to be addressed.

Further work is also required to refine the characteristics of high reliability project organising, differentiating between those that constitute good project management practice in any project environment and those that are specific and necessary to the management of project uncertainty within the domain of safety-critical projects.

Nevertheless, this study provides the first empirical evidence for high reliability organising in response to project uncertainty in two critical infrastructure sectors. What remains unproven is a causal relationship between the adoption of high reliability project organising, and the safer, more timely and cost efficient delivery of projects. For example, the ever increasing budgets and timescales for new nuclear plants in the UK and France (c.f. BBC, 2015; WNN, 2015) and anecdotal evidence from a number of current UK decommissioning projects points to a nuclear project delivery culture that is indeed ultra-safe, that is highly reliable in a technical sense, but may be less reliable in terms of delivering project outcomes in a timely and cost efficient manner.

\section{Conflicts of interest}

There are no conflicts of interest in this study.

\section{Acknowledgements}

The authors would like to thank the anonymous reviewers, whose detailed comments have strengthened the originally submitted manuscript.

\section{References}

Barton, M. A., Sutcliffe, K. M., Vogus, T. J., \& Dewitt, T. (2015). Performing under uncertainty: contextualized engagement in wildland firefighting. Journal of Contingencies and Crisis Management, 23(2), 74-83. 
BBC. (2015). Hinkley Point nuclear plant delayed, says EDF. Retrieved September 15, 2015, from http://www.bbc.co.uk/news/business-34149392

Bierly, P. E., \& Spender, J.-C. (1995). Culture and high reliability organizations: the case of the nuclear submarine. Journal of Management, 21(4), 639-656.

Boin, A., \& Schulman, P. (2008). Assessing NASA's safety culture: the limits and possibilities of highreliability theory. Public Administration Review, (Nov/Dec), 1050-1062.

Boin, A., \& van Eeten, M. J. G. (2013). The resilient organization. Public Management Review, 15(3), 429-445. http://doi.org/10.1080/14719037.2013.769856

Brady, T., \& Davies, A. (2010). From hero to hubris - Reconsidering the project management of Heathrow's Terminal 5. International Journal of Project Management, 28(2), 151-157. http://doi.org/10.1016/j.ijproman.2009.11.011

Brooks, J., McCluskey, S., Turley, E., \& King, N. (2015). The utility of Template Analysis in qualitative psychology research. Qualitative Research in Psychology, 12(2), 202-222. http://doi.org/10.1080/14780887.2014.955224

Busby, J., \& Iszatt-White, M. (2014). The relational aspect to high reliability organization. Journal of Contingencies and Crisis Management, 22(2), 69-80. http://doi.org/10.1111/1468-5973.12045

Cassell, C. (2011). Interviews in Organisational Research. In D. A. Buchanan \& A. Bryman (Eds.), The Sage Handbook of Organisational Research Methods Paperback Edition (pp. 500-515). London, UK: Sage Publications Ltd.

Chassin, M. R., \& Loeb, J. M. (2013). High-reliability health care: getting there from here. The Milbank Quarterly, 91(3), 459-90. http://doi.org/10.1111/1468-0009.12023

Cogent. (2009). Power people: The civil nuclear workforce 2009-2025 Renaissance Nuclear Skills Series 1. Retrieved September 15, 2015, from http://www.cogentskills.com/media/1086/nuclearreportpowerpeople.pdf

Crawford, L., Morris, P., Thomas, J., \& Winter, M. (2006). Practitioner development: from trained technicians to reflective practitioners. International Journal of Project Management, 24(8), 722-733. http://doi.org/10.1016/j.ijproman.2006.09.010

Creed, W. E. D., Stout, S. K., \& Roberts, K. H. (1993). Organisational Effectiveness as a Theoretical Foundation for Research on Reliability Enhancing Organisations. In K. H. Roberts (Ed.), New Challenges to Understanding Organisations (pp. 55-74). New York: Macmillan.

Crowley, C., Harré, R., \& Tagg, C. (2002). Qualitative research and computing: methodological issues and practices in using QSR NVivo and NUD*IST. International Journal of Social Research Methodology, 5(3), 193-197. http://doi.org/10.1080/13645570210146258

Daft, R. L., \& Weick, K. E. (1984). Toward a model of organizations as interpretation systems. The Academy of Management Review, 9(2), 284-295. http://doi.org/10.2307/258441

Davies, A., \& Mackenzie, I. (2014). Project complexity and systems integration: constructing the London 2012 Olympics and Paralympics Games. International Journal of Project Management, 32(5), 773-790. http://doi.org/10.1016/j.ijproman.2013.10.004

Demchak, C. C. (1996). Tailored precision armies in fully networked battlespace: high reliability organisational dilemmas in the information age. Journal of Contingencies and Crisis Management, 4(2), 93-103.

Denyer, D., Kutsch, E., Lee-Kelley, E. (Liz), \& Hall, M. (2011). Exploring reliability in information systems programmes. International Journal of Project Management, 29(4), 442-454. http://doi.org/10.1016/j.ijproman.2011.02.002

Gebauer, A. (2012). Mindful organizing as a paradigm to develop managers. Journal of Management Education, 37(2), 203-228. http://doi.org/10.1177/1052562912458573

Gibbs, G. (2014). Using Software in Qualitative Analysis. In U. Flick (Ed.), The SAGE Handbook of Qualitative Data Analysis (pp. 277-294). London, UK: Sage Publications Ltd.

Gladwell, M. (2006). Blink: The Power of Thinking without Thinking. London, UK: Penguin Group. 
Grix, J. (2010). The Foundations of Research (2nd ed.). UK: Palgrave Macmillan.

Guba, E. G., \& Lincoln, Y. S. (1998). Competing Paradigms in Qualitative Research. In N. K. Denzin \& Y. S. Lincoln (Eds.), The Landscape of Qualitative Research: Theories and Issues. London, UK: Sage Publications Ltd.

Hansen, M. T., Nohria, N., \& Tierney, T. (1999). What's Your Strategy for Managing Knowledge? In J. A. Woods \& J. Cortada (Eds.), The Knowledge Management Yearbook 2000-2001 (p. 5569). New York.: Routledge.

Hollnagel, E., Woods, D. D., \& Leveson, N. (2006). Resilience Engineering: Concepts and Precepts. Farnham, UK: Ashgate Publishing Ltd.

Hopkins, A. (2014). Issues in safety science. Safety Science, 67, 6-14. http://doi.org/10.1016/j.ssci.2013.01.007

Kettunen, J., Reiman, T., \& Wahlström, B. (2007). Safety management challenges and tensions in the European nuclear power industry. Scandinavian Journal of Management, 23(4), 424-444. http://doi.org/10.1016/j.scaman.2007.04.001

King, N. (2004). Using Templates in the Thematic Analysis of Text. In C. Cassell \& G. Symon (Eds.), Essential Guide to Qualitative Methods in Organizational Research (pp. 256-270). London, UK: Sage Publications Ltd.

Klein, R. L., Bigley, G. A., \& Roberts, K. H. (1995). Organizational culture in high reliability organizations: an extension. Human Relations, 487(7), 771-793.

La Porte, T. (1988). The United States Air Traffic System: Increasing Reliability in the Midst of Rapid Growth. In R. Mayntz \& T. Hughes (Eds.), The Development of Large Scale Technical Systems (pp. 215-244). Boulder,Co: Westview Press.

La Porte, T. (1996). High reliability organizations: unlikely demanding and at risk. Journal of Contingencies and Crisis Management, 4(2), 60-71.

Leveson, N., Dulac, N., Marais, K., \& Carroll, J. (2009). Moving beyond normal accidents and high reliability organizations: a systems approach to safety in complex systems. Organization Studies, 30(2-3), 227-249. http://doi.org/10.1177/0170840608101478

Lundin, R. A., \& Soderholm, A. (1995). A theory of the temporary organisation. Scandinavian Journal of Management, 11(4), 437-455.

Mannarelli, T., Roberts, K. H., \& Bea, R. G. (1996). Learning how organizations manage risk. Journal of Contingencies and Crisis Management, 4(2), 83-92.

Morse, J. M. (1994). Designing Funded Qualitative Research. In N. K. Denzin \& Y. S. Lincoln (Eds.), Handbook of Qualitative Research (pp. 428-444). London: Sage Publications Ltd.

Myers, K. K. (2005). A burning desire: assimilation into a fire department. Management Communication Quarterly, 18(3), 344-384.

Oedewald, P., \& Gotcheva, N. (2015). Safety culture and subcontractor network governance in a complex safety critical project. Reliability Engineering \& System Safety, 141, 106-114. http://doi.org/10.1016/j.ress.2015.03.016

Olde Scholtenhuis, L. L., \& Doree, A. G. (2013). Welcoming high reliability organising in construction management. In S. D. Smith \& D. D. Ahiaga-Dagbui (Eds.), Proceedings 29th Annual ARCOM Conference (pp. 939-948). Reading, UK.

Perin, C. (2005). Shouldering Risks: The Culture of Control in the Nuclear Power Industry. New Jersey: Princeton University Press.

Perrow, C. (1984). Normal Accidents: Living with High Risk Technologies. New York: Basic Books.

Reich, B. H., Liu, L., Sauer, C., Bannerman, P., Cicmil, S., Cooke-Davies, T., ... Thomas, J. (2013). Developing better theory about project organizations. International Journal of Project Management, 31, 938-942. http://doi.org/10.1016/j.ijproman.2013.07.001

Reiman, T., Rollenhagen, C., Pietikäinen, E., \& Heikkilä, J. (2015). Principles of adaptive management in complex safety-critical organizations. Safety Science, 71, 80-92. http://doi.org/10.1016/j.ssci.2014.07.021 
Rijpma, J. A. (1997). Complexity, tight-coupling and reliability: connecting normal accidents theory and high reliability theory. Journal of Contingencies and Crisis Management, 5(1), 15-23. http://doi.org/10.1111/1468-5973.00033

Roberts, K. H., \& Bea, R. (2001). Must accidents happen? lessons from high reliability organizations. Academy of Management Executive, 15(3), 70-78.

Roberts, K. H., \& Rousseau, D. M. (1989). Research in nearly failure-free, high reliability organizations: having the bubble. IEEE Transactions on Engineering Management, 36(2), 132-139.

Rochlin, G. I. (1993). Defining High Reliability Organizations in Practice: a Taxonomic Prologue. In K. H. Roberts (Ed.), New Challenges to Understanding Organizations (pp. 11-32). New York: Macmillan.

Rochlin, G. I. (2011). How to hunt a very reliable organization. Journal of Contingencies and Crisis Management, 19(1), 14-20. http://doi.org/10.1111/j.1468-5973.2010.00626.x

Rochlin, G. I., La Porte, T., \& Roberts, K. H. (1987). The self-designing high reliability organization: aircraft carrier flight operations at sea. Naval War College Review, 40, 76-90.

Roe, E., \& Schulman, P. R. (2008). High Reliability Management: Operating on the Edge. Stanford,CA: Stanford University Press.

Roe, E., Schulman, P. R., van Eeten, M. J. G., \& de Bruijne, M. (2004). High-reliability bandwidth management in large technical systems: findings and implications of two case studies. Journal of Public Administration Research and Theory, 15(2), 263-280. http://doi.org/10.1093/jopart/mui015

Ruchlin, H. S. (2004). The role of leadership in instilling a culture of safety. Journal of Healthcare Management, 49(1), 47-58.

Sagan, S. D. (1993). The Limits of Safety: Organizations, Accidents, and Nuclear Weapons. Princeton, NJ.: Princeton University Press.

Saunders, F. C. (2015). Toward high reliability project organizing in safety-critical projects. Project Management Journal, 46(3), 25-35. http://doi.org/10.1002/pmj

Saunders, F. C., Gale, A. W., \& Sherry, A. H. (2015). Conceptualising uncertainty in safety-critical projects: a practitioner perspective. International Journal of Project Management, 33(2), 467-478. http://doi.org/10.1016/j.ijproman.2014.09.002

Schatzki, T. R. (2006). On organizations as they happen. Organization Studies, 27(12), 1863-1873. http://doi.org/10.1177/0170840606071942

Schulman, P. R. (1993). The Analysis of High -Reliability Organizations: A Comparative Framework. In K. H. Roberts (Ed.), New Challenges to Understanding Organizations (pp. 33-54). New York: Macmillan.

Sullivan, J., \& Beach, R. (2009). Improving project outcomes through operational reliability: a conceptual model. International Journal of Project Management, 27(8), 765-775. http://doi.org/10.1016/j.ijproman.2009.02.006

Taleb, N. N. (2007). The Black Swan: The Impact of the Highly Improbable. London, UK: Penguin Books.

Thomas, D., Fox, R., \& Miller, C. (2015). Voices from the field: wildland fire managers and high-reliability organizing mindfulness. Society \& Natural Resources, 28, 825-838. http://doi.org/10.1080/08941920.2015.1014590

Thorogood, J. L. (2013). Is there a place for high-reliability organizations in drilling ? SPE Drilling \& Completion, 28(3), 263-269.

Turner, J. R., \& Mueller, R. (2003). On the nature of the project as a temporary organization. International Journal of Project Management, 21, 1-8.

Tversky, A., \& Kahneman, D. (1982). Judgement Under Uncertainty: Heuristics and Biases. In D. Kahneman, P. Slovic, \& A. Tversky (Eds.), Judgement Under Uncertainty: Heuristics and Biases (pp. 3-20). Cambridge.: Cambridge University Press.

Vidal, R. (2015). Managing uncertainty: the engineer, the craftsman and the gardener. Journal of Contingencies and Crisis Management, 23(2), 106-116. http://doi.org/10.1111/1468-5973.12081 
Vidal, R., \& Roberts, K. H. (2014). Teams : the triad effect. Journal of Contingencies and Crisis Management, $22(1), 18-28$.

Wears, R. L. (2012). Rethinking healthcare as a safety-critical industry. Work, 41, 4560-4563. http://doi.org/10.3233/WOR-2012-0037-4560

Weick, K. E., \& Sutcliffe, K. (2007). Managing the Unexpected. San Francisco: John Wiley and Sons.

Weick, K. E., Sutcliffe, K. M., \& Obstfeld, D. (1999). Organizing for High Reliability: Processes of Collective Mindfulness. In R. S. Sutton \& B. M. Staw (Eds.), Research in Organizational Behaviour, Volume 1 (pp. 81-123). Stanford, CA.: Jai Press.

Williams, T. (2009). Decisions made on scant information. In T. M. Williams, K. Samset, \& K. S. Sunnevag (Eds.), Making Essential Choices with Scant Information; Front End Decision Making in Projects (pp. 317). Basingstoke: Palgrave Macmillan.

Winch, G. M. (2010). Managing Construction Projects: An Information Processing Approach (2nd ed.). Chichester, UK: Wiley-Blackwell.

WNN. (2015). Flamanville EPR timetable and costs restructured. Retrieved September 15, 2015, from http://www.world-nuclear-news.org/NN-Flamanville-EPR-timetable-and-costs-revised-0309154.html 